\title{
A monoclonal antibody reacting with a determinant on leptospiral lipopolysaccharide protects guinea pigs against leptospirosis
}

\author{
B. H. JOST, B. ADLER, T. VINH, and S. FAINE \\ Department of Microbiology, Monash University, Clayton, 3168, Victoria, Australia
}

\begin{abstract}
Summary. An IgA monoclonal antibody (MUM/F1-1/copenhageni) was produced from a mouse immunised with Leptospira interrogans serovar copenhageni. The antibody showed partial serogroup specificity by agglutination and by reaction in enzyme immunoassay, and opsonised homologous leptospires for phagocytosis by cultured mouse macrophages. Immunodiffusion and Western-blotting experiments indicated that MUM/F1-1/copenhageni reacted with a carbohydrate determinant in the leptospiral lipopolysaccharide. Daily administration of purified MUM/F1-1/ copenhageni $\operatorname{IgA}$ before and after challenge with $2 \times 10^{8}$ virulent homologous leptospires passively protected newborn guinea pigs against lethal leptospirosis.
\end{abstract}

\section{Introduction}

It is well established that development of a humoral immune response during leptospirosis is important in resistance to infection (Adler and Faine, 1976, 1977, 1978 $a$ and $b$; Adler et al., 1980a). Immunity appears to depend on the production of agglutinating, opsonising antibody; cell-mediated immune mechanisms have no detectable role. Although the immune response to infection with leptospires is well documented, the nature of the antigens important in protection remains unclear. Many preparations of leptospiral antigens have been reported (Faine, 1974) but only a few have been purified for definitive study. One of these antigens, the leptospiral lipopolysaccharide (LPS) structurally resembles endotoxins of other gramnegative bacteria, although it has different chemical and biological properties (Vinh et al., 1986). As leptospiral LPS elicits the production of protective antibody during infection (Adler and Faine, 1978a and $b$ ), it is possible the LPS is an important protective antigen. Antibodies against LPS from other gram-negative organisms can be used to passively protect against homologous infection and LPS can also be used as an immunogen against experimental infection (Pennington and Kuchmy, 1980; Colwell et al., 1984; Kirkland and Ziegler, 1984; Sawada et al., 1984).

To determine the nature of the leptospiral anti-

Received 4 Feb. 1986; accepted 23 Apr. 1986. gens that stimulate the production of protective antibody, monoclonal antibodies (MCAs) have been produced. This strategy has been used successfully for other organisms, notably the malaria parasite Plasmodium (Potocnjak et al., 1980; Holder and Freeman, 1981; Boyle et al., 1982). Antileptospiral MCAs have been described (Ono et al., 1982, 1984; Adler and Faine, $1983 a$ and $b$; Kobayashi et al., 1984), but have been mainly of taxonomic significance. If these MCAs can be used to passively protect against infection in a suitable animal model, they should be useful to identify and characterise potential protective antigens whose determinants could be the basis for immunogens suitable for human and veterinary use.

This paper reports the production and characterisation of a protective MCA directed against a determinant on the leptospiral LPS.

\section{Materials and methods}

\section{Leptospires}

Leptospira interrogans serovar copenhageni strain designated $\mathrm{H} 45$ in this laboratory was isolated from a rat (Faine and van der Hoeden, 1964) and serovar copenhageni strain L136 was provided by Professor R. Yanagawa, Hokkaido University, Sapporo, Japan. L. illini serovar illini was obtained from A.D. Alexander, Walter Reed Medical Center, Washington D.C., USA. The other leptospiral serovars used in this study were provided by N. Stallman, W.H.O. Leptospira Reference Laboratory, 
Brisbane, Australia. Cultivation and enumeration of leptospires were as described by Adler and Faine (1976).

\section{Antigens, antisera and serological methods}

Leptospiral LPS was prepared by the method of Westphal and Jann (1965), with the modification that the LPS was finally purified by centrifugation at $105000 \mathrm{~g}$ for $3 \mathrm{~h}$. LPS polysaccharide fraction was prepared by boiling LPS $1 \mathrm{mg} / \mathrm{ml}$ in acetic acid $1.5 \% \mathrm{v} / \mathrm{v}$ for $2 \mathrm{~h}$ (Naess and Hofstad, 1984). The precipitated lipid was removed by centrifugation at $400 \mathrm{~g}$ and the supernate was used as the polysaccharide fraction of LPS. Protease treatment of LPS was by overnight incubation of LPS $50 \mu \mathrm{g} / \mathrm{ml}$ with Proteinase K (Sigma) $40 \mu \mathrm{g} / \mathrm{ml}$ at $37^{\circ} \mathrm{C}$. Leptospiral sonicate antigens were prepared as previously described (Adler et al., 1980b) and a phenol-extracted LPS preparation, designated TM antigen (Shinagawa and Yanagawa, 1972), was the kind gift of Professor R. Yanagawa, Hokkaido University, Sapporo, Japan. The preparation of mouse antisera was described by Tu et al. (1982), and the methods for performing the microscopic agglutination test (MAT), enzyme immunoassay (EIA) and gel immunodiffusion were described by Adler and Faine (1983a). Subclasses of mouse immunoglobulin were determined by reaction with specific anti-mouse immunoglobulins (Nordic Immunologicals, Tilburg, The Netherlands) in gel immunodiffusion.

\section{Production of monclonal antibodies}

Adult female Balb/c mice were immunised intraperitoneally (ip) with $0.5 \mathrm{ml}$ of a suspension of serovar copenhageni strain $\mathrm{H} 452.5 \times 10^{8}$ leptospires $/ \mathrm{ml}$ grown in low protein EMJH medium (Bey and Johnson, 1978) and washed once in physiological saline. Four weeks later the mice received a similar, booster injection. After 3 days, spleen cells were harvested and $10^{8}$ spleen cells were fused with $10^{7}$ NS-1 (P3-X63-Ag8.653) myeloma cells by the method of Kohler and Milstein (1975). The fusion mixture was dispensed into two 24-well tissue culture trays (Costar) which contained $5 \times 10^{4}$ mouse macrophages/well. Resultant hybridomas were grown in Dulbecco Modified Eagle's Medium (DME, Microbiological Associates, Bethesda, MD, USA) supplemented with fetal calf serum $10 \%$ v/v (FCS, Commonwealth Serum Laboratories, Australia). MAT and EIA were used to screen undiluted hybridoma supernates for specific antibody. Antibody-positive cultures were cloned by limiting dilution in 96-well Costar tissue culture trays with a cloning medium of $\mathbf{L} 929$-conditioned medium $25 \% \mathrm{v} / \mathrm{v}$ in DME supplemented with FCS 15\% v/v (DME-15\% FCS). L929-conditioned medium consisted of DME-10\% FCS in which mouse fibroblasts (cell line L929, Commonwealth Serum Laboratories, Australia) had been cultured for 2 days at $37^{\circ} \mathrm{C}$. All hybrids were cloned at least twice and were grown to extinction in large volumes of DME$10 \%$ FCS. The cells were removed by centrifugation and the culture supernate was treated by precipitation with $50 \%$ saturated ammonium sulphate (Goding, 1980) to purify the immunoglobulin fraction. Monoclonal antibody (MCA) levels were determined by absorbance at 280 nm.

\section{Polyacrylamide gel electrophoresis and Western blotting}

Leptospiral antigens were separated by electrophoresis according to the method of Laemmli (1970) on a $1 \mathrm{~mm}$ thick discontinuous SDS-polyacrylamide $15 \% \mathrm{w} / \mathrm{v}$ gel in a Bio-Rad Protean II gel box for $4 \mathrm{~h}$. Resolved antigens were electrophoretically transferred on to nitrocellulose membranes (Bio-Rad, USA) by the method of Towbin et al. (1979) with a 1 in 2 dilution of the described transfer buffer, in a Bio-Rad Transblot cell for $3 \mathrm{~h}$ at $60 \mathrm{~V}$. Immunological detection of specific antigens was performed with a peroxidase-conjugated second antibody with chloro-1-naphthol as the chromogen by the method of Hawkes et al. (1982). Western-blotted membranes were stained for protein by Penguin India Ink $0.1 \% \mathrm{w} / \mathrm{v}$ in PBS containing tween $200.3 \% \mathrm{v} / \mathrm{v}$ (Merck, West Germany). Gels were stained for LPS by the modified silver stain of Tsai and Frasch (1982).

\section{Opsonisation assays}

Mouse macrophages for in-vitro opsonisation of leptospires for phagocytosis were prepared as described by Tu et al. (1982). L. interrogans serovar copenhageni strain $\mathrm{H} 452 \times 10^{8}$ cells were added to Leighton tubes containing macrophage monolayers. Dilutions of hybridoma culture supernate, antiserum, normal mouse serum (NMS) or DME-10\% FCS were also added and the tubes were incubated and fixed as described (Tu et al., 1982), in preparation for indirect immunofluorescence staining. The second antibody used was a 1 in 20 dilution of fluoroisothiocyanate-conjugated anti-mouse immunoglobulin (Wellcome Diagnostics, Australia).

The methods for generation and measurement of the chemiluminescence (CL) response by phagocytic cells were as described by McGrath et al. (1984), but with mouse macrophages. Macrophages were harvested into warm DME-10\% FCS by peritoneal lavage and samples containing $1 \times 10^{6}$ macrophages in $1-\mathrm{ml}$ volumes were pipetted into glass vials. The vials were incubated for $1 \mathrm{~h}$ at $37^{\circ} \mathrm{C}$ in a humidified $\mathrm{CO}_{2}$ incubator before measurement of CL.

\section{Passive protection experiments}

Outbred guinea pigs of either sex, weighing less than $100 \mathrm{~g}$ and obtained from the Monash University animal house, were given ip injections of $2 \times 10^{8}$ leptospires of a virulent serovar copenhageni strain L136 in EMJH medium. The virulence of the leptospires was maintained by continuous passage in guinea pigs. Infected guinea pigs always died within 3-4 days of challenge. To confirm that death was due to acute leptospirosis, all dead animals were examined post mortem and samples of blood, liver and kidneys removed aseptically, emulsified in 5-ml 
volumes of EMJH medium and incubated at $30^{\circ} \mathrm{C}$ for up to 21 days or until viable leptospires could be detected by dark-ground microscopy. At autopsy, infected animals consistently displayed distinctive pathological changes indicative of acute leptospirosis which included extensive haemorrhaging of the peritoneal and abdominal walls, peri-renal haemorrhages and extensive jaundice. Leptospires could also be cultured from various sites. Guinea pigs given similar volumes of sterile EMJH medium were killed after 4 days and were normal on autopsy. In this model, death of the animal with a characteristic pathology and the presence of live leptospires were considered to be the criteria of lethal leptospiral infection. A group of three guinea pigs each received $175 \mu \mathrm{g}$ of purified F1-1c IgA MCA ip $1 \mathrm{~h}$ before challenge with $2 \times 10^{8}$ virulent $L$. interrogans serovar copenhageni strain L136. These animals subsequently received four similar doses of F1-1c IgA at daily intervals. To determine passively-acquired serum antibody levels, guinea pigs were bled by cardiopuncture after pentobarbitone anaesthesia and antibody titres in the separated serum were determined by MAT.

\section{Results}

\section{Serological specificity}

MUM/F1-1/copenhageni (designated F1-1c) was an IgA class antibody which reacted in both the microscopic agglutination test (MAT) and enzyme immunoassay (EIA). The antibody agglutinated 11 of the 17 serovars of the Icterohaemorrhagiae serogroup, but did not react significantly with representative serovars of the other serogroups of L. interrogans or other species of Leptospira. Representative members of all other $L$. interrogans serogroups, $L$. biflexa serovar patoc and $L$. illini were tested. For all non-reactive serovars the MAT titres were zero and the EIA optical density values were at background level (table). Those serovars agglutinated by F1-1c also reacted by EIA with the exceptions of serovar naam and the cross-reactive canicola serovar (table).

\section{Nature of the antigen}

F1-1c IgA reacted in immunodiffusion with purified homologous LPS, TM and sonicate antigens to produce lines of identity (fig. 1). An additional precipitin band visible with LPS was not observed when the antigen was boiled before testing. This pattern of reactivity is often seen for leptospiral LPS suggesting that the LPS exists in different aggregation states. The MCA also reacted with these antigens in EIA (results not shown).

Homologous LPS $1 \mu \mathrm{g}$ and LPS polysaccharide fraction $5 \mu \mathrm{g}$ were resolved by electrophoresis on polyacrylamide gels $15 \% \mathrm{w} / \mathrm{v}$ and silver-stained (fig.
Table Specificity of F1-1c antibody reactions as measured by microscopic agglutination test (MAT) and enzyme immunoassay (EIA)

\begin{tabular}{llrr}
\hline $\begin{array}{l}\text { Serogroup of } \\
\text { L. interrogans }\end{array}$ & Serovar & $\begin{array}{r}\text { MAT } \\
\text { titre* }\end{array}$ & $\begin{array}{c}\text { EIA† } \\
\%\end{array}$ \\
\hline Icterohaemorrhagiae & copenhageni & 65536 & 100 \\
& bog-vere & 2048 & 71 \\
& budapest & 8192 & 104 \\
dakota & 2048 & 87 \\
& icterohaemorrhagiae & 2048 & 120 \\
& mankarso & 12800 & 120 \\
& monymusk & 4096 & 130 \\
& naam & 1024 & - \\
& ndabhambukuje & 512 & 63 \\
& sarmin & 128 & 30 \\
& weaveri & 2048 & 81 \\
& birkini & 0 & - \\
& gem & 0 & - \\
& mwogolo & 0 & - \\
& ndambari & 0 & - \\
smithi & 0 & - \\
tonkini & 0 & - \\
& canicola & 4 & - \\
\hline
\end{tabular}

* Expressed as highest dilution showing agglutination. $\dagger$ Expressed as percentage of OD at $488 \mathrm{~nm}$ obtained by heterologous EIA compared with homologous copenhageni EIA (0.80).

$-=$ EIA OD $\leqslant$ background level.

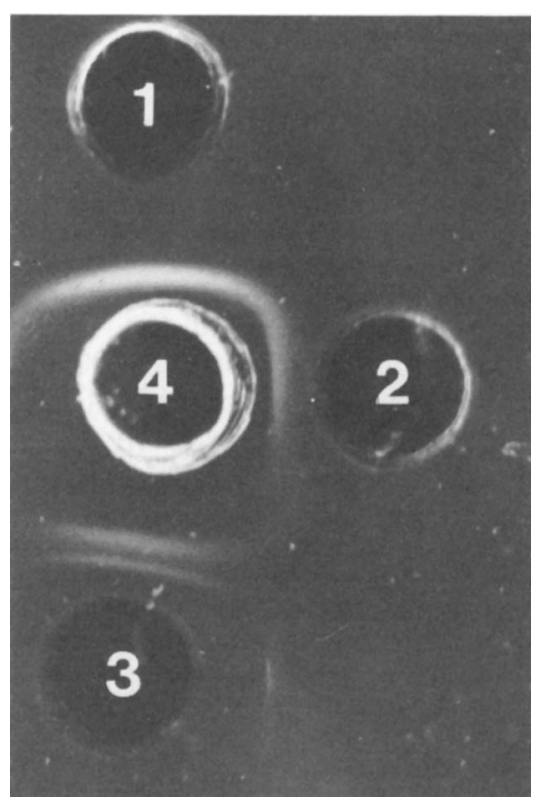

Fig. 1. Immunodiffusion reactions $(20-\mu \mathrm{l}$ volumes of serovar copenhageni antigen preparations with F1-lc antibody: (1) Sonicate (equivalent to $1 \times 10^{10}$ leptospires $\left./ \mathrm{ml}\right)$, (2) TM $(400 \mu \mathrm{g} /$ $\mathrm{ml}$ ), (3) LPS (400 $\mu \mathrm{g} / \mathrm{ml}),(4)$ F1-1c MCA (culture supernate, $20 \times$ concentrated); $20-\mu$ l volume were added to each well. 


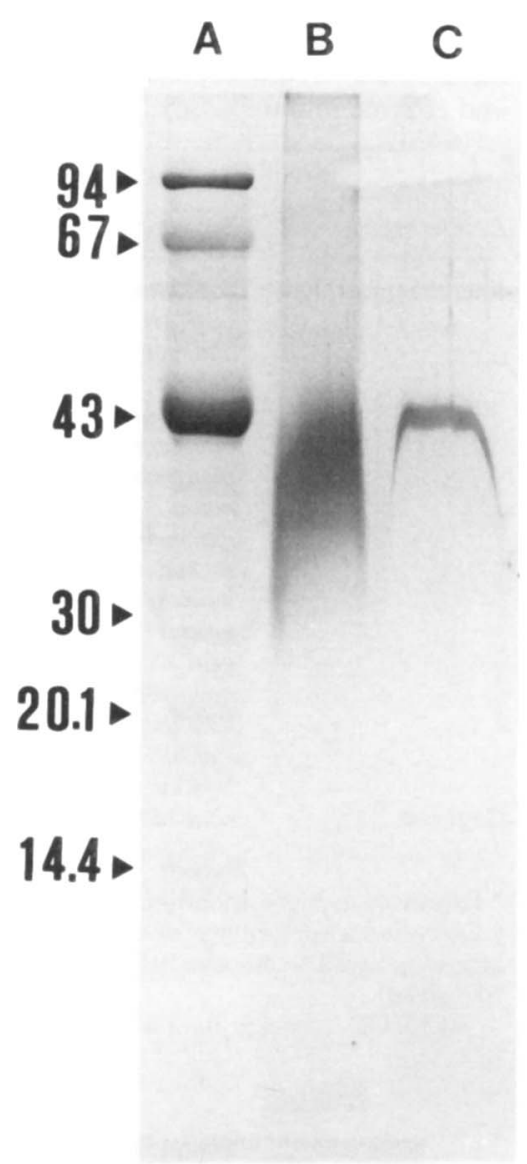

(a)
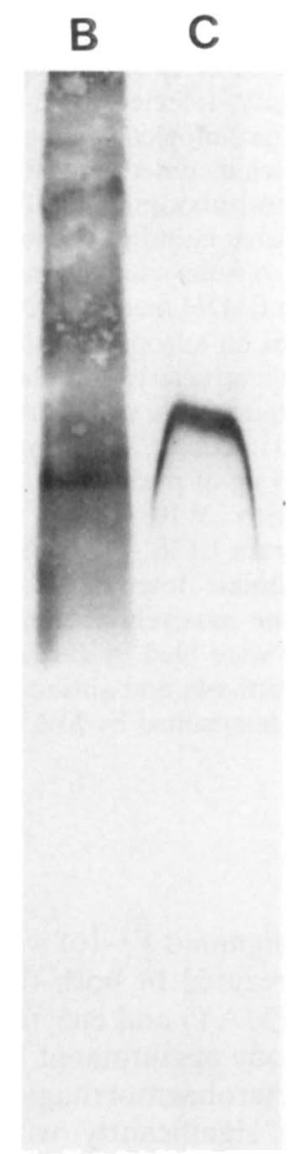

(b)

Fig. 2. SDS-polyacrylamide gel electrophoresis of serovar copenhageni antigen preparations: (a) profile obtained by silver staining; (b) profile obtained by Western-blot analysis with F1-lc MCA. Lanes: (A) Mol-wt markers, with mol. wts (10 ${ }^{3}$ ); (B) $1 \mu \mathrm{g} \mathrm{LPS;} \mathrm{(C)} 5 \mu \mathrm{g}$ LPS polysaccharide fraction.

2a) or Western-blotted and immuno-stained with purified Fl-1c IgA $20 \mu \mathrm{g} / \mathrm{ml}$ (fig. 2b). Control immunoblots were stained with 1 in 200 dilutions of mouse anti-copenhageni serum or NMS as positive and negative controls respectively. The profile observed with the mouse anti-copenhageni serum was similar to that with the MCA (not illustrated). F1-Ic reacted with the resolved LPS producing a smear of staining unlike the characteristic pattern of discrete bands often seen with protein antigens, but similar to that described for LPS from other bacteria (Linko-Kettunen et al., 1984). However when LPS polysaccharide fraction was used as the antigen, the smear was resolved into a discrete, characteristically arched band of mol. wt $c .44000$ (fig. 2b). A similar band was detected by silver staining (fig. 2a). Reaction of purified LPS polysaccharide fraction with Fl-1c suggested that the specific epitope was of a carbohydrate nature. This result was confirmed by the reaction of F1-1c with protease-treated LPS in EIA. Treatment of LPS with Proteinase $\mathrm{K}$ did not alter its EIA reactivity, which showed that the determinant was resistant to proteolysis.

\section{Opsonisation experiments}

Mouse macrophages were used to test the opsonic capacity of F1-1c culture supernate, both by $C L$ and by indirect immunofluorescent (IF) staining. Vials containing macrophages were incubated with $1 \times 10^{8}$ cells of $L$. interrogans serovar copenhageni strain $\mathrm{H} 45$ and CL was measured continuously. No significant change in CL response was observed when either NMS or DME-10\% FCS were introduced. However, addition of mouse anti-copenhageni antiserum or F1-1c culture supernate resulted in CL responses of $2.00 \mathrm{mV}$ and $2.14 \mathrm{mV}$ respect- 
ively (fig. 3). The responses peaked after 5-7 $\mathrm{min}$ and slowly declined to base levels in $30-40 \mathrm{~min}$. Addition of a 1 in 50 dilution of fresh guinea-pig serum as a source of complement did not significantly alter the responses observed. Similarly mouse macrophages co-incubated with leptospires and 1 in $500 \mathrm{NMS}$ or 1 in $20 \mathrm{DME}-10 \% \mathrm{FCS}$ and stained by indirect IF showed no fluorescence, in contrast to macrophages treated with 1 in 500 mouse anticopenhageni antiserum (MAT titre, 512) as a positive control or 1 in $20 \mathrm{~F} 1-1 \mathrm{c}$ culture supernate (MAT titre, 4096), which were strongly fluorescent, with fluorescent-staining leptospires seen attached to and within the macrophages.

\section{Passive protection}

The capacity of F1-1c antibody to passively protect against infection was investigated. Initial experiments indicated that passively-acquired serum levels of F1-1c decreased rapidly from titres of 32 to $2-4$ in less than $24 \mathrm{~h}$. Animals receiving only a single dose of $175 \mu \mathrm{g}$ of MCA were not protected against challenge, therefore repeated doses of F1-1c antibody were administered daily to ensure that passive serum MAT titres of 32-64 were maintained. A group of three control animals which received physiological saline in place of antibody, followed by challenge, all died within 3-4 days with typical autopsy findings indicative of acute leptospirosis (see Materials and methods). In contrast the three animals given F1-1c antibody survived, and

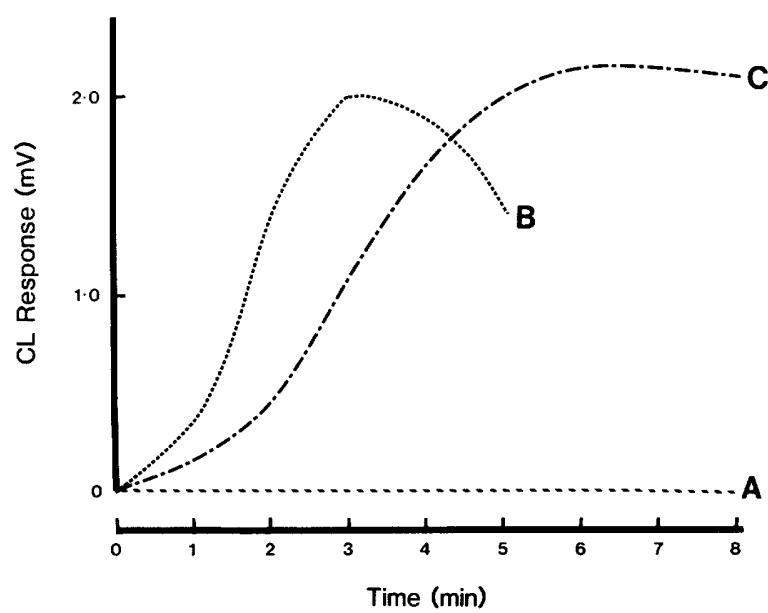

Fig. 3. Chemiluminescence (CL) response of mouse macrophages after interaction with $L$. interrogans serovar copenhageni (H45) with the following additions: A, 1 in 500 normal mouse serum or 1 in 20 DME- $10 \% ; \mathrm{B}, 1$ in 500 mouse anti-copenhageni antiserum; C, 1 in $20 \mathrm{Fl}-1 \mathrm{c}$ monoclonal antibody. when killed 14 days after challenge were normal at autopsy. Viable leptospires were not detected in blood, liver or kidney cultures taken from these animals at autopsy.

A passive serum agglutination titre of 16-32 in these animals was sufficient to protect. However, protection was not afforded by passive serum titres of 4 and, therefore, the minimum protective agglutinating titre of this antibody must lie somewhere in the range $4-32$.

\section{Discussion}

This paper reports the production of an $\operatorname{IgA}$ monoclonal antibody directed against a partially serogroup-specific determinant found on leptospiral LPS of some but not all Icterohaemorrhagiae serogroup members. The MCA did not react significantly with serovars outside the Icterohaemorrhagiae serogroup. Those serovars that reacted in MAT were also reactive in EIA with the exception of serovar naam and the cross-reactive canicola serovar. Serovar naam did not react significantly in EIA although it was strongly agglutinated by the MCA (table). This unusual reactivity is commonly seen with other anti-leptospiral LPS MCAs and may reflect reactions with minor determinants on the leptospires (Ono et al., 1982; Farrelly et al., 1985; Jost et al., 1985). The cross-reaction between serovar canicola and the MCA was much lower than reactions between MCA and homologous serogroup members. This Icterohaemorrhagiae-Canicola cross-reaction is commonly observed with specific rabbit antisera, possibly indicating conservation of some minor epitope (Kmety, 1967).

Kobayashi et al. (1984) have also reported the production of MCAs directed against serovars of the Icterohaemorrhagiae serogroup and described the identification of serovar-specific determinants. However the authors only tested their MCAs against two serovars (icterohaemorrhagiae and copenhageni) from this serogroup. The results of the present study and of other workers (Ono et al., 1982; Farrelly et al., 1985) show that MCAs can cross-react widely with different serovars of the same serogroup. Therefore it is difficult to determine the sero-specificity of an epitope by testing only a small number of serovars.

F1-1c reacted with purified LPS and the TM antigen of Shinagawa and Yanagawa (1972) to produce a line of identity. Reaction of F1-1c with both LPS and TM suggests that the specific epitope occurs in both these antigens and that both are LPS preparations as previously described for serovar pomona (Adler and Faine, 1983a). 
The determinant to which the MCA was directed was present in the polysaccharide fraction of the leptospiral LPS. Silver staining revealed that only one band was present after electrophoretic resolution of the fraction. This band was also detected immunologically by staining the Western-blotted polysaccharide fraction with MCA. The reactive band was characteristically arched, indicative of serovar copenhageni LPS and polysaccharide fraction (unpublished observations).

F1-1c antibody also opsonised viable leptospires for phagocytosis and was further shown to protect against lethal infection in susceptible animals. The results of the passive protection experiment showed that a polysaccharide moiety of leptospiral LPS was important in immunity to infection with leptospires. Our results with F1-1c MCA have identified at least one protective epitope. Reaction with the epitope divided the group taxonomically in that the epitope was not present in all members of the Icterohaemorrhagiae serogroup. There is insufficient information to predict cross-protection between those with and those without the epitope.

In experimental infections of rabbits (Adler and Faine, 1978b) and naturally-acquired infections in man (Adler and Faine, 1978a) a predominant antiLPS response has been documented. The antibodies produced in response to leptospiral infection were agglutinating, suggesting that agglutinating anti-

\section{REFERENCES}

Adler B, Faine S 1976 Susceptibility of mice treated with cyclophosphamide to lethal infection with Leptospira interrogans serovar pomona. Infection and Immunity 14:703-708.

Adler B, Faine S 1977 Host immunological mechanisms in the resistance of mice to leptospiral infections. Infection and Immunity 17:67-72.

Adler B, Faine S 1978a The antibodies involved in the human immune response to leptospiral infection. Journal of Medical Microbiology 11:387-400.

Adler B, Faine S $1978 b$ Serological and protective-antibody responses of rabbits to leptospiral antigens. Journal of Medical Microbiology 11:401-409.

Adler B, Faine S 1983a A Pomona serogroup-specific. agglutinating antigen in Leptospira, identified by monoclonal antibodies. Pathology 15:247-250.

Adler B, Faine S $1983 b$ Species-specific and genus-specific antigens in Leptospira, revealed by monoclonal antibodies and enzyme immunoassay. Zentralblatt für Bakteriologie Mikrobiologie, und Hygiene. 1 Abteilung Originale $A$ 255:317-322.

Adler B, Faine S, Muller H K, Green D E $1980 a$ Maturation of humoral immune response determines the susceptibility of guinea pigs to leptospirosis. Pathology 12:529-538.

Adler B, Faine S, Yanagawa R $1980 b$ Comparative studies on two antigens (F4 and TM) extracted from leptospires. Journal of Clinical Microbiology 12:7-9.

Bey R F. Johnson, R C 1978 Protein-free and low-protein media body may be important in immunity to this disease. This is similar to the role of anti-LPS antibodies produced during infection with other gram-negative organisms.

Immunity to leptospirosis, whether experimental or naturally acquired appears at best to be serogroup-specific which compares with the limited intra-group serological specificity of F1-1c and the other anti-leptospiral LPS MCAs reported so far (Ono et al., 1982; Adler and Faine, 1983a; Farrelly et al., 1985; Jost et al., 1985; Farrelly et al., 1986). There also appears to be cross-immunity between serovars unrelated by agglutination (Kemenes, 1964; Plesko and Lataste-Dorolle, 1970), although the nature of these antigens and their roles in immunity are not understood.

The results suggest an important role for leptospiral LPS in immunity to leptospirosis and provide evidence that anti-LPS antibodies are important in protection from experimental infection. If the polysaccharide fraction of the LPS is important as a protective antigen, then it may be suitable for use in a vaccine. Knowledge of the protective antigens involved in immunity to leptospirosis is clearly necessary for the development of effective vaccines for prophylaxis and control of this disease.

This work was supported by a grant from the National Health and Medical Research Council, Canberra, Australia.

for the cultivation of Leptospira. Infection and Immunity 19:562-569.

Boyle D B, Newbold C I, Smith C C, Brown K N 1982 Monoclonal antibodies that protect in vivo against Plasmodium chabaudi recognise a 250000 -dalton parasite polypeptide. Infection and Immunity 38:94-102.

Colwell D E, Michalek S M, Briles D E, Jirillo E, McGhee J R 1984 Monoclonal antibodies to Salmonella lipopolysacharide: anti-O-polysaccharide antibodies protect $\mathrm{C} 3 \mathrm{H}$ mice against challenge with virulent Salmonella typhimurium. Journal of Immunology 133:950-957.

Faine S 1974 Leptospiral antigens. Folia Facultatis Medicae, Universitatis Comenianae Bratislaviensis 12 Suppl: 57-74.

Faine S, van der Hoeden J 1964 Virulence-linked colonial and morphological variation in Leptospira. Journal of Bacterio$\log _{y}$ 88: 1493-1496.

Farrelly H E, Adler B, Faine S 1985 Serological determinants on leptospiral lipopolysaccharide revealed by monoclonal antibodies. Australian Microbiologist 6:169.

Farrelly H E, Adler B, Faine S 1986 Opsonic monoclonal antibodies against lipopolysaccharide antigens of Leptospira interrogans serovar hardjo. Journal of Medical Microbiology 22:000 000 .

Goding J W 1980 Monoclonal antibodies: principles and practice. Academic Press, London.

Hawkes R, Niday E, Gordon J 1982 A dot-immunobinding assay for monoclonal and other antibodies. Analytical Biochemistry 119:142-147.

Holder A A, Freeman R R 1981 Immunization against blood- 
stage rodent malaria using purified parasite antigens. Nature 294:361-364.

Jost B H, Adler B, Faine S 1985 An agglutinating, opsonizing monoclonal antibody reacting with a determinant in leptospiral lipopolysaccharide. Australian Microbiologist 6:173.

Kemenes F 1964 Cross-immunity studies on virulent strains of leptospires belonging to different serotypes. Zeitschrift für Immunitäts- und Allergieforschung 127:209-229.

Kirkland T N, Zeigler E J 1984 An immunoprotective monoclonal antibody to lipopolysaccharide. Journal of Immunology 132:2590-2592.

Kmety E 1967 Faktorenanalyse von Leptospiren der Icterohaemorrhagiae und einiger verwandter Serogruppen, Vydavatelstvo Slovenskej Akademie Vied, Bratislava.

Kobayashi Y et al. 1984 Characterization of monoclonal antibodies against etiological agents of Weil's disease. Microbiology and Immunology 28:359-370.

Köhler G, Milstein C 1975 Continuous cultures of fused cells secreting antibody of predefined specificity. Nature 256:495-497.

Laemmli U K, 1970 Cleavage of structural proteins during the assembly of the head of bacteriophage T4. Nature 227:680 685.

Linko-Kettunen L, Arstila P, Jalkanen M, Jousimies-Somer H, Lassila O, Lehtonen O-P, Weintraub A, Viljanen M K 1984 Monoclonal antibodies to Bacteroides fragilis lipopolysaccharide. Journal of Clinical Microbiology 20:519-524.

McGrath H, Adler B, Vinh T, Faine S 1984 Phagocytosis of virulent and avirulent leptospires by guinea-pig and human polymorphonuclear leukocytes in vitro. Pathology 16:243249.

Naess V, Hofstad T 1984 Chemical studies of partially hydrolysed lipopolysaccharides from four strains of Campylobacter jejuni and two strains of Campylobacter coli. Journal of General Microbiology 130:2783-2789.

Ono E, Naiki M, Yanagawa R 1982 Production and characterization of monoclonal antibodies to lipopolysaccharide antigen of Leptospira interrogans serovar kremastos and canicola. Zentralblatt für Bakteriologie Mikrobiologie und Hygiene 1 Abteilung Originale A. 252:414-424.
Ono E, Naiki M, Yanagawa R 1984 Isolation of antigenic oligosaccharide fraction from Leptospira interrogans serovar canicola with a monoclonal antibody. Journal of General Microbiology 130:1429-1435.

Pennington J E, Kuchmy D 1980 Mechanism for pulmonary protection by lipopolysaccharide Pseudomonas vaccine. Journal of Infectious Diseases 142:191-198.

Plesko I, Lataste-Dorolle C 1970 Intertype immunity relations of Leptospira strains belonging to the "Australis" serogroup. Biologia (Bratislava) 25:403-412.

Potocnjak P, Yoshida N, Nussenzweig R S, Nussenzweig V 1980 Monovalent fragments (Fab) of monoclonal antibodies to a sporozoite surface antigen $(\mathrm{Pb} 44)$ protect mice against malarial infection. Journal of Experimental Medicine 151:1504-1513.

Sawada S, Suzuki M, Kawamura T, Fujinaga S, Masuho Y, Tomibe K 1984 Protection against infection with Pseudomonas aeruginosa by passive transfer of monoclonal antibodies to lipopolysaccharides and outer membrane proteins. Journal of Infectious Diseases 150:570-576.

Shinagawa M, Yanagawa R 1972 Isolation and characterization of a leptospiral type-specific antigen. Infection and Immunity 5:12-19.

Towbin H, Staehelin T, Gordon J 1979 Electrophoretic transfer of proteins from polyacrylamide gels to nitrocellulose sheets: Procedure and some applications. Proceedings of the National Academy of Science of the USA 76:4350-4354.

Tsai C-M, Frasch C E 1982 A sensitive silver stain for detecting lipopolysaccharide in polyacrylamide gels. Analytical Biochemistry 119:115-119.

Tu V, Adler B, Faine S 1982 The role of macrophages in the protection of mice against leptospirosis: In vitro and in vivo studies. Pathology 14:463-468.

Vinh T, Adler B, Faine S 1986 Ultrastructure and chemical composition of lipopolysaccharide extracted from Leptospira interrogans serovar copenhageni. Journal of General Microbiology 132:103-109.

Westphal O, Jann K 1965 Bacterial lipopolysaccharides. Extraction with phenol-water and further applications of the procedure. Methods in Carbohydrate Chemistry 5:83-91. 